\title{
Nitrogen-Doped Graphene: The Influence of Doping Level on the Charge-Transfer Resistance and Apparent Heterogeneous Electron Transfer Rate
}

\author{
Maria Coros ${ }^{1, *}$, Codruta Varodi ${ }^{1}$, Florina Pogacean ${ }^{1}$, Emese Gal ${ }^{2}$ and Stela M. Pruneanu ${ }^{1, *(D)}$ \\ 1 National Institute for Research and Development of Isotopic and Molecular Technologies, Donat Street, No. \\ 67-103, 400293 Cluj-Napoca, Romania; codruta.varodi@itim-cj.ro (C.V.); florina.pogacean@itim-cj.ro (F.P.) \\ 2 Department of Chemistry and Chemical Engineering, Hungarian Line of Study, Babes-Bolyai University, \\ 11 Arany János St., 400028 Cluj-Napoca, Romania; gal.emese.81@gmail.com \\ * Correspondence: maria.coros@itim-cj.ro (M.C.); stela.pruneanu@itim-cj.ro (S.M.P.)
}

Received: 19 February 2020; Accepted: 23 March 2020; Published: 25 March 2020

check for updates

\begin{abstract}
Three nitrogen-doped graphene samples were synthesized by the hydrothermal method using urea as doping/reducing agent for graphene oxide (GO), previously dispersed in water. The mixture was poured into an autoclave and placed in the oven at $160{ }^{\circ} \mathrm{C}$ for 3,8 and $12 \mathrm{~h}$. The samples were correspondingly denoted NGr-1, NGr-2 and NGr-3. The effect of the reaction time on the morphology, structure and electrochemical properties of the resulting materials was thoroughly investigated using scanning electron microscopy (SEM) Raman spectroscopy, X-ray powder diffraction (XRD), Fourier-transform infrared spectroscopy (FTIR), X-ray photoelectron spectroscopy (XPS), elemental analysis, Cyclic Voltammetry (CV) and electrochemical impedance spectroscopy (EIS). For $\mathrm{NGr}-1$ and NGr-2, the nitrogen concentration obtained from elemental analysis was around $6.36 \mathrm{wt} \%$. In the case of NGr-3, a slightly higher concentration of $6.85 \mathrm{wt} \%$ was obtained. The electrochemical studies performed with NGr modified electrodes proved that the charge-transfer resistance $\left(R_{c t}\right)$ and the apparent heterogeneous electron transfer rate constant $\left(\mathrm{K}_{\mathrm{app}}\right)$ depend not only on the nitrogen doping level but also on the type of nitrogen atoms found at the surface (pyrrolic-N, pyridinic-N or graphitic-N). In our case, the NGr-1 sample which has the lowest doping level and the highest concentration of pyrrolic- $\mathrm{N}$ among all nitrogen-doped samples exhibits the best electrochemical parameters: a very small $\mathrm{R}_{\mathrm{ct}}(38.3 \Omega)$, a large $\mathrm{K}_{\mathrm{app}}\left(13.9 \times 10^{-2} \mathrm{~cm} / \mathrm{s}\right)$ and the best electrochemical response towards 8-hydroxy-2'-deoxyguanosine detection (8-OHdG).
\end{abstract}

Keywords: nitrogen-doped graphene; charge-transfer resistance; apparent heterogeneous electron transfer rate; modified electrodes; detection of 8-OHdG

\section{Introduction}

Graphene, a single layer of graphite, possesses various interesting properties such as large surface area, high thermal and electrical conductivity and good optical transparency [1-3]. Currently, the chemical doping of graphene is an active area of research which continues to grow very quickly. Doping graphene with heteroatoms such as nitrogen $[4,5]$, boron $[6,7]$, sulfur $[8,9]$ or halogens $[10,11]$ can adjust the electronic and electrochemical properties of the material leading to enhanced performances. Among the heteroatoms, nitrogen has drawn a lot of attention due to the significantly improved properties of the N-graphene as part of fuel cells [12], lithium ion batteries [13], supercapacitors [14] or advanced catalyst support $[15,16]$. Nitrogen doping can be achieved using different approaches: mixing graphene with nitrogen containing precursor and thermal annealing [17,18]; thermal exfoliation of graphite oxide in ammonia atmosphere [19]; solvothermal or hydrothermal methods using graphene oxide and Shift base precursors [20-22], chemical vapor deposition [23] or microwave plasma [24]. The hydrothermal 
method was employed for large-scale production of nitrogen-doped graphene $[25,26]$. The preparation of nitrogen-doped graphene using hydrothermal methods was realized using different dopants such as melamine [27,28], hydrazine and ammonia [29], ammonium carbonate [30], 1,4-butanediamine [31], ethylenediamine [32], etc. As an example, Kamali and Golsheikh [33] synthesized well-dispersed, nitrogen-doped graphene, through the hydrothermal reduction of graphene oxide in the presence of ammonia. Nitrogen-doped graphene hydrogels were prepared using graphene oxide as raw material and nine amino acids with different acidities as doping agents [34]. Xing et al. [35] have used a simple one-step hydrothermal method by employing hexamethylenetetramine as single carbon and nitrogen source. Depending on the synthesis method, the nitrogen doping level can reach 9-11 at.\% [36]. Besides this, the performance of the material is strongly influenced by the number of layers present within the graphene flakes. It has been demonstrated that the electronic structure of graphene changes rapidly with the number of layers, reaching the 3D limit of graphite at 10 layers [37]. Nitrogen-doped graphenes have been intensively investigated for their electrochemical behavior due to their capacity to improve electrical conductivity [36]. N-graphene exhibited enhanced electro-catalytic activity and showed potential applications in electrochemical sensors (8-hydroxy-2'-deoxyguanosine, adenine, guanine, thymine and cytosine) $[38,39]$ and energy devices $[40,41]$.

In this paper, we present for the first time the influence of the reaction time on the morphology, structure and electrochemical properties of nitrogen-doped graphenes. We show that the hydrothermal reaction may produce high quality nitrogen -doped graphene with very low charge-transfer resistance $\left(\mathrm{R}_{\mathrm{ct}}\right)$ and large apparent heterogeneous electron transfer rate constant $\left(\mathrm{K}_{\mathrm{app}}\right)$. In addition, we originally proved the relationship between these two parameters and the electro-catalytic effect of $\mathrm{N}$-doped graphene towards the detection of cancer biomarker, 8-hydroxy-2'-deoxyguanosine (8-OHdG).

\section{Materials and Methods}

\subsection{Chemicals and Materials}

Potassium ferrocyanide- $\mathrm{K}_{4}\left[\mathrm{Fe}(\mathrm{CN})_{6}\right]$ and potassium chloride $(\mathrm{KCl})$ were purchased from Merck (Germany). N,N-dimethylformamide (DMF) was bought from Sigma-Aldrich (Germany). 8-hydroxy-2'-deoxyguanosine (8-OHdG) was purchased from the Cayman Chemical Company. For the synthesis of nitrogen-doped graphene the following chemicals were used: graphene oxide, prepared using a modified Hummers method as previously reported [42], and urea (Alfa-Aesar, Germany).

\subsection{Instruments}

The morphological and structural characterization of the samples was performed with: scanning electron microscope (SU-8230 STEM system, Hitachi, Japan); X-ray powder diffraction (Bruker D8 Advance Diffractometer)(Germany); Fourier transform infrared spectroscopy (Bruker Tensor II spectrometer) (Germany); Raman spectroscopy (JASCO (NRS 3300) spectrophotometer) (USA); and X-ray photoelectron spectroscopy (SPECS spectrometer, equipped with a dual-anode X-ray source $\mathrm{Al} / \mathrm{Mg}$, a PHOIBOS 150 2DCCD hemispherical energy analyzer and a multi-channeltron detector) (Germany). Elemental analysis of the synthesized samples was performed with an elemental analyzer-FLASH EA 1112 (Italy).

For electrochemical measurements (cyclic voltammetry-CV, linear sweep voltammetry-LSV, and electrochemical impedance spectroscopy-EIS) a potentiostat/galvanostat instrument (PGSTAT-302N, Metrohm-Autolab B.V., Utrecht, The Netherlands) connected to a three-electrode cell and controlled by PC was employed. The counter electrode was a large area platinum foil $\left(2 \mathrm{~cm}^{2}\right)$, while the reference was an $\mathrm{Ag} / \mathrm{AgCl}$ electrode $(3 \mathrm{M} \mathrm{KCl})$. The $\mathrm{CV}$ and LSV measurements were generally run from -0.2 to $+0.8 \mathrm{~V}$ vs. $\mathrm{Ag} / \mathrm{AgCl}$, at various scan rates $\left(2,5,10,15,20,30,40\right.$ and $\left.50 \mathrm{mV} \cdot \mathrm{s}^{-1}\right)$. The EIS spectra were recorded over $0.1-10^{6} \mathrm{~Hz}$ range $(10 \mathrm{mV}$ amplitude excitation signal) at the peak potential of each electrode, and the experimental data were fitted using Nova 1.11 software (Metrohm-Autolab B.V., Utrecht, The Netherlands). 


\subsection{Synthesis of Nitrogen-Doped Graphene}

Three nitrogen-doped graphene samples were synthesized by the hydrothermal method using urea as doping and reducing agent for graphene oxide (GO), as reported before [43] (Scheme 1). Typically, an appropriate amount of urea was added to $150 \mathrm{~mL}$ aqueous dispersion of GO, previously sonicated for $25 \mathrm{~min}$. The mixture was poured into a $250 \mathrm{~mL}$ autoclave and placed in the oven at $160^{\circ} \mathrm{C}$ for different periods of time $(3,8$ and $12 \mathrm{~h})$. The samples were correspondingly denoted NGr- 1 , NGr-2 and NGr-3. The reduction of GO was observed immediately after the reaction was finished: the well-dispersed brown solution (GO in water) became a clear yellowish solution with a black solid deposited at the bottom of the autoclave. After cooling to room temperature, each sample was filtered, washed with distilled water and dried by lyophilization. Finally, all samples were thermally treated at $300{ }^{\circ} \mathrm{C}$ in Ar flow, for $15 \mathrm{~min}$, to remove the excess urea and the residual oxygen-containing groups.

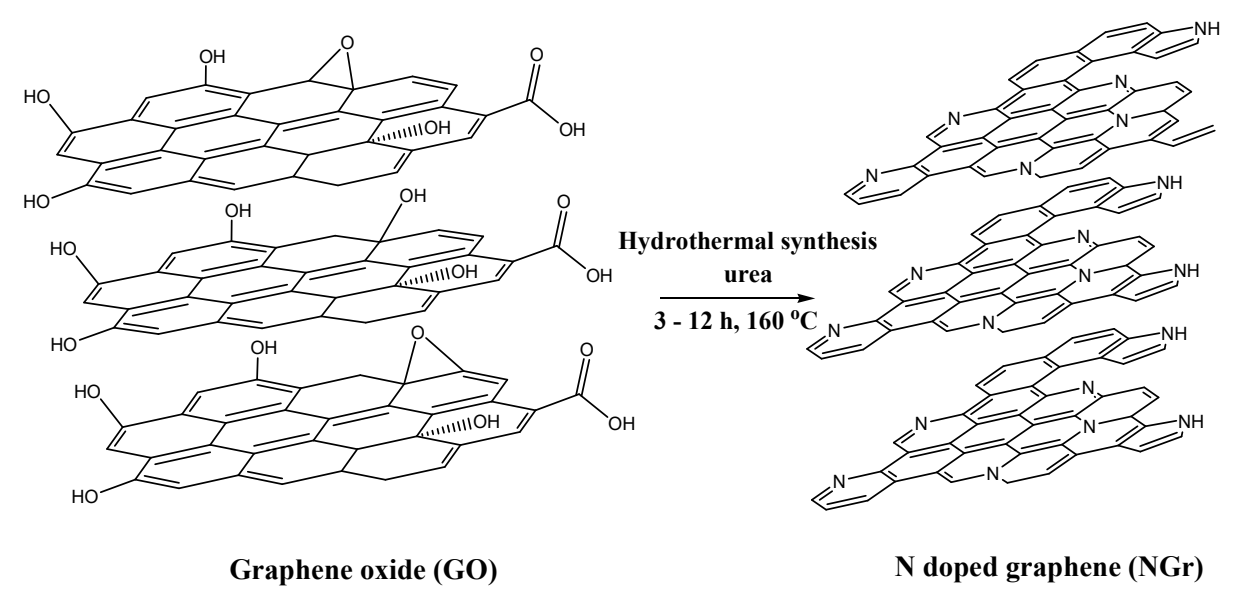

Scheme 1. Schematic representation of nitrogen-doped graphene prepared using the hydrothermal method.

\subsection{Modification of Glassy-Carbon Electrodes with Graphene-Based Materials}

The nitrogen-doped graphenes (NGr-1, NGr-2, NGr-3) and GO were individually dispersed in $N, N$-dimethylformamide $(1 \mathrm{mg} / \mathrm{mL})$ for three minutes with an ultrasonic finger device (SONICS Vibra-Cell). The obtained graphene suspensions were then used to modify four glassy carbon (GC) electrodes. Before modification, the electrodes were polished on a felt cloth then washed with a large quantity of double-distilled water $(20 \mathrm{~mL})$ and dried at room temperature. Next, a volume of $10 \mu \mathrm{L}$ of graphene suspension $(1 \mathrm{mg} / \mathrm{mL})$ was drop-casted onto each GC surface and used for electrochemical investigation, after $24 \mathrm{~h}$ drying at room temperature. The modified electrodes were correspondingly denoted as GC/NGr-1, GC/NGr-2, GC/NGr-3, and GC/GO. Before CV or EIS measurements, the bare GC and graphene-modified electrodes were cycled in potassium ferrocyanide solution (10 cycles between -0.2 to $+0.65 \mathrm{~V}$ vs. $\mathrm{Ag} / \mathrm{AgCl}$, with $50 \mathrm{mV} / \mathrm{s}$ ).

\section{Results and Discussions}

\subsection{Morphological and Structural Characterization of the Nitrogen-Doped Graphene Samples}

The scanning electron microscopy (SEM) technique was employed for the morphological characterization of the nitrogen-doped graphene. Representative SEM images are presented in Figure 1, where one can see that all the samples have highly wrinkled surfaces. Such disordered morphologies imply weak $\pi-\pi$ stacking interaction, originating from the doping with nitrogen atoms. The samples are formed by large flakes with a linear size in the range of micrometers.

The elemental analysis of the nitrogen-doped samples gave further indication about the doping level. For NGr-1 and NGr-2 samples where the synthesis time was 3 and $8 \mathrm{~h}$ respectively, the heteroatom 
concentration was around $6.36 \mathrm{wt} \%$ (see Table 1). In the case of the NGr-3 sample (12 $\mathrm{h}$ reaction time)a higher concentration was obtained, of $6.85 \mathrm{wt} \%$.
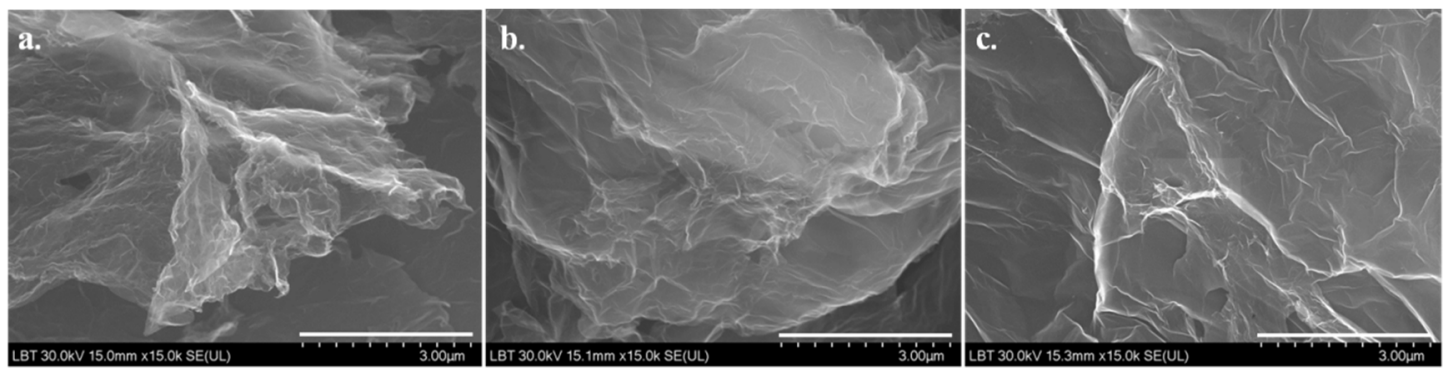

Figure 1. Representative (scanning electron microscopy) SEM images of: NGr-1 (a), NGr-2 (b) and NGr-3 (c); in all images, the scale bar is $3 \mu \mathrm{m}$.

Table 1. Elemental analysis of (graphene oxide) GO and nitrogen-doped graphene samples.

\begin{tabular}{cccccc}
\hline \multirow{2}{*}{ Sample } & \multirow{2}{*}{$\begin{array}{c}\text { Reaction Time } \\
\text { (Hours) }\end{array}$} & \multicolumn{5}{c}{ wt.\% } \\
\cline { 3 - 6 } & 2 & 52.84 & - & 1.53 & 5.63 \\
\hline GO & 3 & 80.57 & 6.36 & 1.39 & 11.68 \\
\hline NGr-1 & 8 & 80.27 & 6.37 & 1.09 & 12.27 \\
\hline NGr-2 & 12 & 80.45 & 6.85 & 1.34 & 11.36 \\
\hline NGr-3 & & & & &
\end{tabular}

Next, the characterization of the nitrogen-doped graphene samples (NGr-1, NGr-2 and NGr-3) was performed using various techniques such as X-ray powder diffraction (XRD), Raman spectroscopy, Fourier-transform infrared spectroscopy (FTIR) and X-ray photoelectron spectroscopy (XPS). Each of them gave valuable information regarding the size of the graphene crystallites, the number of layers and the functionalities attached to the graphene surface.

The X-ray powder diffraction pattern of GO and of the subsequently doped materials NGr-1, NGr-2 and NGr-3 are displayed in Figure 2. One can see that the sharp diffraction peak present at $2 \theta$ $\sim 11^{\circ}$ and indexed to (001) crystal plane of graphene oxide completely disappears after nitrogen doping and reduction reaction, and a new peak at $\sim 22^{\circ}$, attributed to (002) crystal plane of reduced graphene oxide, is visible. The new peak is broader and has lower intensity due to the disorder induced by the nitrogen atoms into the graphene lattice.

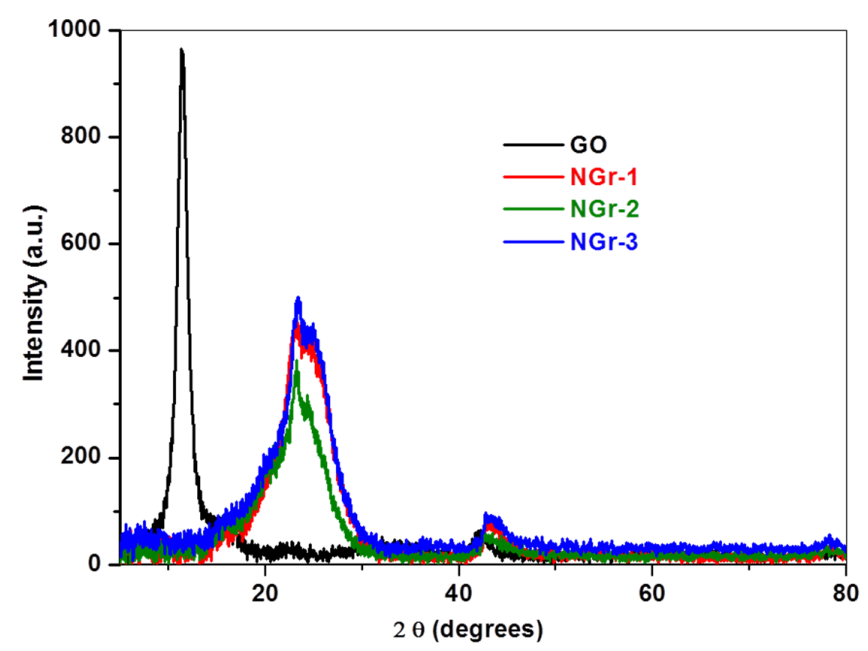

Figure 2. The XRD (X-ray powder diffraction) patterns of GO, NGr-1, NGr-2 and NGr-3 samples. 
The XRD experimental data allowed the calculation of the number of layers $(n)$ present within graphene oxide and nitrogen-doped graphenes, the interlayer distance $(d)$, and the mean crystallite size $(D)$ of graphene. For all nitrogen-doped samples, the asymmetric peak from $22^{\circ}$ was deconvoluted into three theoretical Gaussian peaks (Figure 3). For each peak, the $D$ value was calculated from the full width at half maximum (FWHM) using the Debye-Scherrer equation:

$$
D=\frac{0.9 * \lambda}{\beta * \cos \theta}
$$

where $\lambda$ is the $X$-ray wavelength, $\beta$ is the FWHM expressed in radians, and $\theta$ is half the diffraction angle of the peak (in degrees) corresponding to interlayer distance, $d$. The $d$ value was found with the Bragg equation $(d=\lambda / 2 \sin \theta)$, while the average number of layers, $n$, was calculated from the relation $n=D / d$. Since the N-doped graphene samples are composed of crystallites having different sizes and number of layers, their contribution (expressed in \%) may be determined by dividing the area of each deconvoluted peak to the total area of the diffractogram [44,45] (see Table 2).
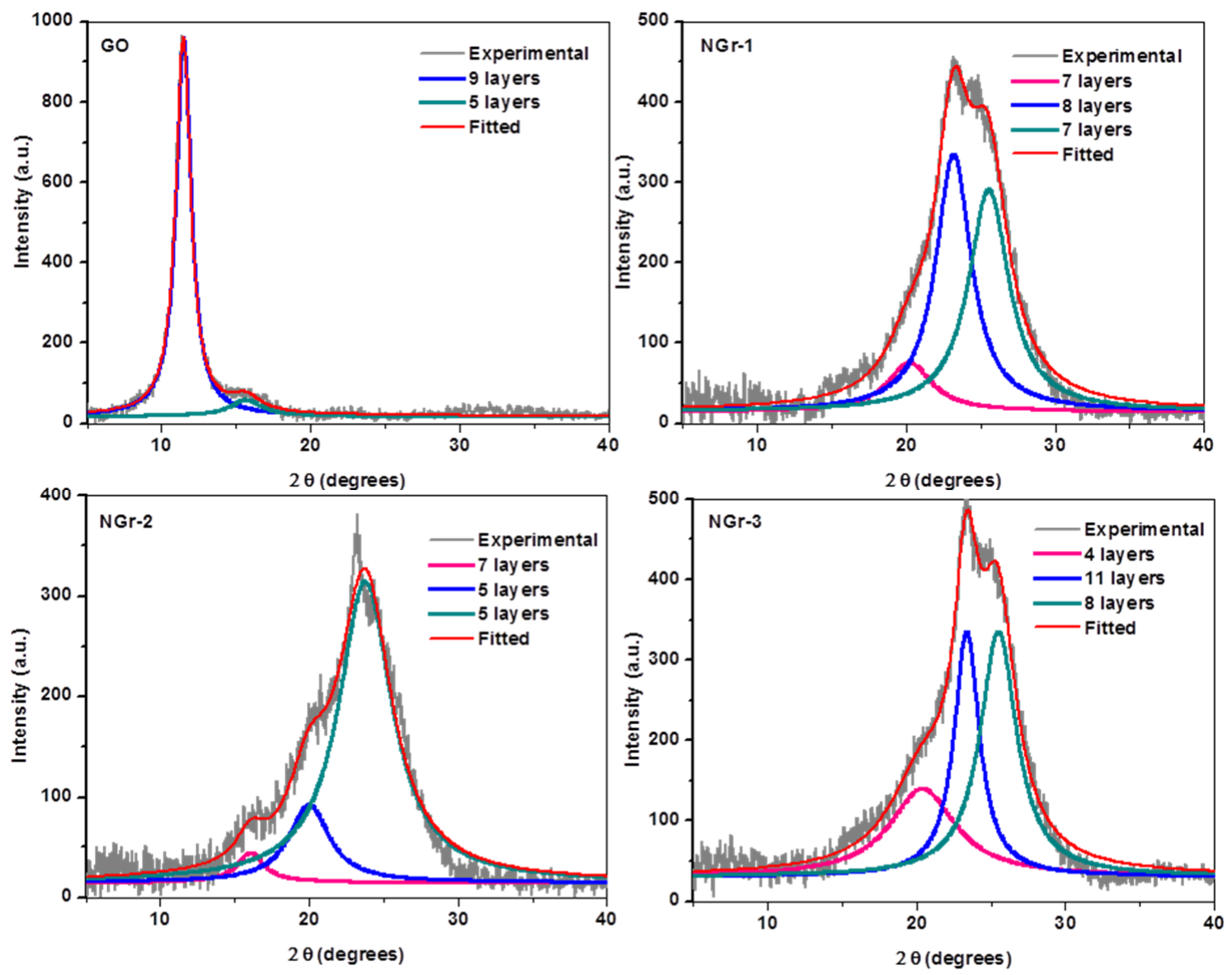

Figure 3. The XRD patterns of GO, NGr-1, NGr-2 and NGr-3 samples and the corresponding deconvoluted peaks.

From Table 2 it can be seen that the interlayer distance of GO and N-doped graphenes is larger than that of graphite $(0.335 \mathrm{~nm})$. The largest value $(0.77 \mathrm{~nm})$ is found in GO sample and is attributed to the oxygen functional groups formed after the strong oxidation treatment of graphite. In this case, the average number of layers is $9(92 \%)$.

In order to evaluate the degree of structural disorder within graphene oxide and nitrogen-doped graphene samples, Raman spectroscopy was carried out (Figure 4). The high fluorescence signal of GO additionally confirms that the material is highly oxidized, being in good agreement with the XRD 
pattern. In the nitrogen-doped graphene samples, three important bands are evidenced: the defect (D) band at $\sim 1360 \mathrm{~cm}^{-1}$, the graphite (G) band located at $\sim 1598 \mathrm{~cm}^{-1}$, and the $2 \mathrm{D}$ band at $\sim 2710 \mathrm{~cm}^{-1}$ (Table 3).

Table 2. Structural parameters obtained from the corresponding XRD pattern of each sample: graphene crystallite size $(D)$, interlayer distance $(d)$, average number of layers $(n)$ and their proportion $(\%)$ in GO, NGr-1, NGr-2 and NGr-3 samples.

\begin{tabular}{cccccc}
\hline Sample & $\boldsymbol{2 \theta}(\mathbf{d e g})$ & $\boldsymbol{D}(\mathbf{n m})$ & $\boldsymbol{d}(\mathbf{n m})$ & $\boldsymbol{n}$ & $\boldsymbol{\%}$ \\
\hline \multirow{2}{*}{ GO } & 11.56 & 6.78 & 0.77 & 9 & 92 \\
& 15.65 & 2.85 & 0.56 & 5 & 8 \\
\hline \multirow{3}{*}{ NGr-1 } & 20.23 & 3.09 & 0.44 & 7 & 11 \\
& 23.16 & 2.88 & 0.38 & 8 & 45 \\
& 25.52 & 2.53 & 0.35 & 7 & 44 \\
\hline \multirow{3}{*}{ NGr-2 } & 16.05 & 4.02 & 0.55 & 7 & 4 \\
& 19.99 & 2.35 & 0.44 & 5 & 16 \\
\hline \multirow{3}{*}{ NGr-3 } & 23.76 & 1.82 & 0.37 & 5 & 80 \\
& 20.39 & 1.66 & 0.43 & 4 & 28 \\
& 23.35 & 4.07 & 0.38 & 11 & 29 \\
\hline
\end{tabular}
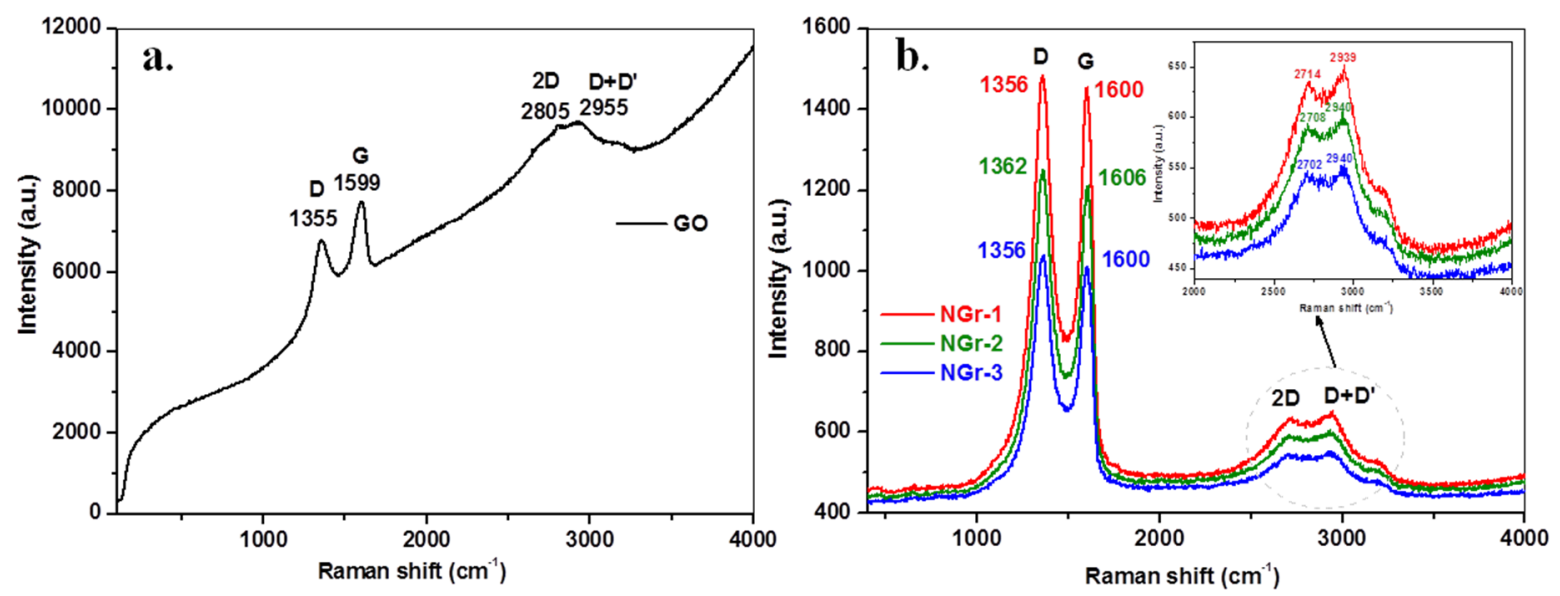

Figure 4. Raman spectra of GO (a) and nitrogen-doped graphene samples (b): NGr-1 (red); NGr-2 (olive); NGr-3 (blue).

Table 3. Structural parameters obtained from the Raman bands of GO, NGr-1, NGr-2 and NGr-3 samples.

\begin{tabular}{|c|c|c|c|c|c|c|c|c|c|c|c|}
\hline Sample & $\begin{array}{c}\mathrm{G} \\
\left(\mathrm{cm}^{-1}\right)\end{array}$ & $\begin{array}{c}I_{G} \\
\text { (a.u.) }\end{array}$ & $\begin{array}{c}D \\
\left(\mathrm{~cm}^{-1}\right)\end{array}$ & $\begin{array}{c}I_{D} \\
\text { (a.u.) }\end{array}$ & $\begin{array}{c}2 \mathrm{D} \\
\left(\mathrm{cm}^{-1}\right)\end{array}$ & $\begin{array}{c}I_{2 D} \\
\text { (a.u.) }\end{array}$ & $\begin{array}{c}\mathrm{D}+\mathrm{D}^{\prime} \\
\left(\mathrm{cm}^{-1}\right)\end{array}$ & $\begin{array}{l}\mathrm{I}_{\mathrm{D}+\mathrm{D}^{\prime}} \\
\text { (a.u.) }\end{array}$ & $\mathbf{I}_{\mathrm{D}} / \mathbf{I}_{\mathrm{G}}$ & $\mathbf{I}_{2 \mathrm{D}} / \mathrm{I}_{\mathrm{G}}$ & $\begin{array}{c}\mathrm{L}_{\mathrm{a}} \\
(\mathrm{nm})\end{array}$ \\
\hline GO & 1599 & 1241 & 1355 & 1203 & 2805 & 600 & 2955 & 629 & 0.97 & 0.48 & 17.11 \\
\hline NGr-1 & 1600 & 1449 & 1356 & 1482 & 2714 & 635 & 2939 & 643 & 1.022 & 0.44 & 16.24 \\
\hline NGr-2 & 1606 & 1212 & 1362 & 1245 & 2708 & 594 & 2940 & 607 & 1.027 & 0.49 & 16.16 \\
\hline NGr-3 & 1600 & 1007 & 1356 & 1040 & 2702 & 548 & 2940 & 552 & 1.03 & 0.54 & 16.12 \\
\hline
\end{tabular}

In addition, the $\mathrm{D}+\mathrm{D}^{\prime}$ band is also present at around $2940-2944 \mathrm{~cm}^{-1}$ and appears in graphene-like materials with structural defects, which explain its presence in the nitrogen doped samples [46]. The 
$\mathrm{I}_{\mathrm{D}} / \mathrm{I}_{\mathrm{G}}$ ratio is related to the in-plane crystallite size $\left(\mathrm{L}_{\mathrm{a}}\right)$, as shown by Equation (2), giving an indication of the defect-free domains [47]:

$$
\mathrm{L}_{\mathrm{a}}(\mathrm{nm})=\frac{560}{\mathrm{E}_{\mathrm{l}}^{4}}\left(\frac{\mathrm{I}_{\mathrm{D}}}{\mathrm{I}_{\mathrm{G}}}\right)^{-1}
$$

where $E_{1}$ represents the laser excitation energy $(2.41 \mathrm{eV})$. The largest $L_{a}$ value was obtained for GO $(17.11 \mathrm{~nm})$ followed by NGr-1 $(16.24 \mathrm{~nm})$ and NGr-2 $(16.16 \mathrm{~nm})$ samples, which according to elemental analysis had similar amounts of nitrogen $(6.36 \mathrm{wt} \%)$. For the NGr-3 sample, the $\mathrm{L}_{\mathrm{a}}$ value is slightly lower $(16.12 \mathrm{~nm})$ being in good agreement with the higher doping level $(6.85 \mathrm{wt} \%)$.

Additionally, FTIR spectroscopy was used to investigate the bonding changes within the carbon atoms after graphene oxide was thermally reduced and doped with nitrogen. The corresponding spectra of GO and of the nitrogen-doped samples NGr-1, NGr-2 and NGr-3 are presented in Figure 5.

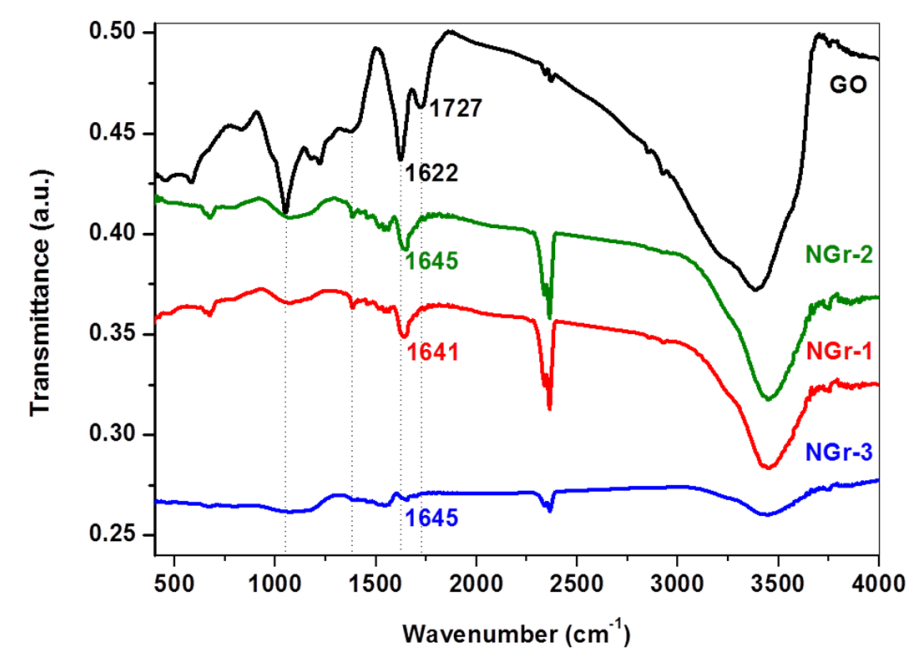

Figure 5. FTIR spectra of GO (black) and of the nitrogen-doped samples NGr-1 (red), NGr-2 (olive) and NGr-3 (blue).

In the FTIR spectrum of GO, due to the extensive oxidation, a strong and broad O-H stretching vibration band appears at $3410 \mathrm{~cm}^{-1}$ along with the characteristic peak of the $\mathrm{C}=\mathrm{O}$ stretching vibration at $1727 \mathrm{~cm}^{-1}$, the $\mathrm{O}-\mathrm{H}$ deformation at $1387 \mathrm{~cm}^{-1}$, the C-O (epoxy) stretching vibration at $1225 \mathrm{~cm}^{-1}$, the $\mathrm{C}-\mathrm{O}$ (alcoxy) stretching vibration at $1050 \mathrm{~cm}^{-1}$ and the epoxy or peroxide group peak at $976 \mathrm{~cm}^{-1}$. After hydrothermal reaction, the intensity of the $3391 \mathrm{~cm}^{-1}$ peak significantly decreases, while the peak at $1727 \mathrm{~cm}^{-1}$, attributed to the $\mathrm{C}=\mathrm{O}$ groups, disappears almost completely. An important feature is the shifting of the peak from $1622 \mathrm{~cm}^{-1}$, correlated to the in-plane vibration of $C=C$, to $1641-1645 \mathrm{~cm}^{-1}$ in the nitrogen-doped samples. This is due to the overlapping of the $\mathrm{C}=\mathrm{C}$ and $\mathrm{C}=\mathrm{N}$ vibrations, which gives further evidence of the insertion of nitrogen containing groups [48].

The amount of nitrogen and the nature of the functional groups present at the surface of the obtained materials were determined using XPS. Figure 6 shows the N1s core-level spectra obtained for the prepared samples. 

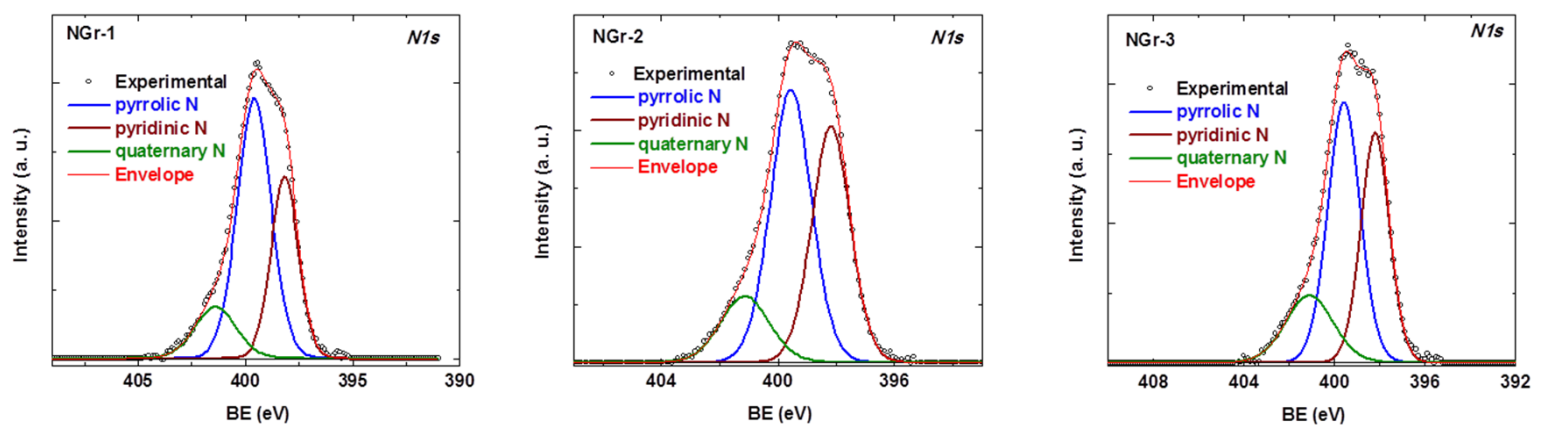

Figure 6. $N$ 1s core-level spectra of NGr-1, NGr-2 and NGr-3 samples.

Each spectrum was deconvoluted into three components, approximately at $398.2 \mathrm{eV}, 399.5 \mathrm{eV}$ and $401.2 \mathrm{eV}$, which were attributed to pyridinic-N, pyrrolic-N and graphitic-N [49], respectively. Based on the spectrum deconvolution, it results that the NGr-1 sample predominantly contains pyrrolic-N (55.4 at.\%). This percentage decreases with the reaction time, therefore the NGr-2 and NGr-3 samples have smaller amounts of 47.6 and 46.3 at.\%, respectively. The NGr-2 sample contains the largest percentage of pyridinic-N (38.6 at.\%) as compared to the other investigated samples. The amount of graphitic-N (quaternary) is comparatively lower in all three samples in relation to the other components identified after the spectra deconvolution. This demonstrates that the hydrothermal treatment of GO with urea results in preferential surface functionalization, depending on the reaction time (Table 4), with significant influence on the electrochemical characteristics of $\mathrm{N}$-graphene modified electrodes. The total amounts of nitrogen with respect to that of carbon were determined to be 0.08 (NGr-1), 0.075 (NGr-2) and 0.074 (NGr-3) (estimated by calculating the ratio between $\mathrm{C} 1 \mathrm{~s}$ and $\mathrm{N} 1 \mathrm{~s}$ peak areas and by considering the sensitivity factors, i.e., nitrogen atoms were supposed to be doped uniformly in the graphitic layers). As can be seen in Table 4, by increasing the reaction time the percentage of pyrrolic-N decreased, while pyridinic- $\mathrm{N}$ and graphite- $\mathrm{N}$ unevenly increased. Therefore, we suggest that at longer reaction time, some pyrrolic-N is converted to pyridinic- $\mathrm{N}$ or graphitic-N. This is due to the fact that during the hydrothermal reaction, urea releases carbimide and $\mathrm{NH}_{3}$. Carbimide reacts with hydroxyl groups of GO to form intermediates after dehydration and rearrangement, resulting in more pyrrolic-N. The possible reaction mechanism was published by Shang et al. [50].

Table 4. Elemental composition and relative atomic ratios of GO and identified $\mathrm{N}$ species as determined from XPS survey and high resolution N1s spectra of the investigated samples.

\begin{tabular}{cccccccc}
\hline \multirow{2}{*}{ Sample } & $\begin{array}{c}\text { Reaction Time } \\
\text { (h) }\end{array}$ & \multicolumn{3}{c}{ XPS Survey (at.\%) } & \multicolumn{3}{c}{ N 1s Core-Level (\%) } \\
\cline { 3 - 7 } & 2 & C & O & N & Pyridinic & Pyrolic & Graphitic \\
\hline GO & 3 & 70.7 & 29.3 & - & - & - & - \\
\hline NGr-1 & 8 & 85.6 & 6.8 & 7.5 & 31.1 & 55.4 & 13.5 \\
\hline NGr-2 & 87.2 & 6.1 & 6.6 & 38.6 & 47.6 & 13.8 \\
\hline NGr-3 & 12 & 85.9 & 7.6 & 6.4 & 36 & 46.3 & 17.7 \\
\hline
\end{tabular}

Measurements of the high-resolution XPS spectra of C1s and O1s were also achieved and the results are shown in Table 5. 
Table 5. Assignment of each deconvoluted peak based on their binding energies (BE) and atomic concentrations [AC, \%] for GO, NGr-1, NGr-2 and NGr-3 samples.

\begin{tabular}{|c|c|c|c|c|c|}
\hline \multirow{2}{*}{ Elements } & \multicolumn{4}{|c|}{ Binding Energy (eV)/[at.\%] } & \multirow{2}{*}{ Assignments } \\
\hline & GO & NGr-1 & NGr-2 & NGr-3 & \\
\hline \multirow{5}{*}{ C1s } & $\begin{array}{c}284.43 \\
(31.2 \%)\end{array}$ & $284.5 \mathrm{eV}(39.6 \%)$ & $284.4 \mathrm{eV}(44.4 \%)$ & $284.4 \mathrm{eV}(41.8 \%)$ & $\mathrm{C}=\mathrm{C}$ \\
\hline & $\begin{array}{l}285.4 \\
(11 \%)\end{array}$ & $285 \mathrm{eV}(38.9 \%)$ & $285 \mathrm{eV}(25.6 \%)$ & $285.2 \mathrm{eV}(31.4 \%)$ & $\mathrm{C}-\mathrm{C}$ \\
\hline & - & $286.6 \mathrm{eV}(13.9 \%)$ & $286.2 \mathrm{eV}(19.8 \%)$ & $286.7 \mathrm{eV}(17.6 \%)$ & $\mathrm{C}-\mathrm{N}$ \\
\hline & $\begin{array}{c}287.75 \\
(9 \%) \\
\end{array}$ & $288.6 \mathrm{eV}(4.7 \%)$ & $288.8 \mathrm{eV}(7 \%)$ & $289.9 \mathrm{eV}(6 \%)$ & $\mathrm{C}=\mathrm{O}$ \\
\hline & $\begin{array}{c}289.3 \\
(1.35 \%)\end{array}$ & $290.9 \mathrm{eV}(2.9 \%)$ & $291.2 \mathrm{eV}(3.2 \%)$ & $291.9 \mathrm{eV}(3 \%)$ & $\mathrm{O}-\mathrm{C}=\mathrm{O}$ \\
\hline \multirow{3}{*}{ O 1s } & $\begin{array}{c}531.8 \\
(4.87 \%)\end{array}$ & $530.6 \mathrm{eV}(42.3 \%)$ & $530.4 \mathrm{eV}(33 \%)$ & $530.4 \mathrm{eV}(32.9 \%)$ & $\mathrm{C}=\mathrm{O}$ \\
\hline & $\begin{array}{c}532.72 \\
(22.45 \%)\end{array}$ & $532.1 \mathrm{eV}(31.7 \%)$ & $531.9 \mathrm{eV}(37.3 \%)$ & $531.9 \mathrm{eV}(43.3 \%)$ & $-\mathrm{OH}$ \\
\hline & $\begin{array}{l}533.4 \\
(0.89)\end{array}$ & $533.5 \%(25.9 \%)$ & $533.1 \mathrm{eV}(24.8 \%)$ & $533.1 \mathrm{eV}(23.7 \%)$ & $\mathrm{O}-\mathrm{C}=\mathrm{O}$ \\
\hline
\end{tabular}

A comparison of synthetic details of previously reported similar nitrogen-doped graphene is summarized in Table 6.

Table 6. Comparison of different nitrogen-doped graphene samples prepared from urea and graphene oxide, using the hydrothermal method.

\begin{tabular}{ccccc}
\hline GO: Urea (Weight) & Temperature $\left({ }^{\circ} \mathbf{C}\right)$ & Reaction Time (h) & Nitrogen Content (at.\%) & Ref. \\
\hline $1: 3$ & 190 & 12 & - & {$[51]$} \\
\hline $1: 60$ & 180 & $2-18$ & 7.6 & {$[52]$} \\
\hline $1: 300$ & 180 & 12 & - & {$[53]$} \\
\hline $1: 300$ & 180 & 12 & 11.36 & {$[54]$} \\
\hline $1: 390$ & 180 & 12 & 6.05 & {$[55]$} \\
\hline $1: 30$ & 160 & 3 & 6.61 & {$[56]$} \\
\hline $1: 30$ & 160 & 3 & 7.5 & [57] \\
\hline $1: 10$ & 160 & 3 & 6.6 & This work \\
\hline $1: 10$ & 160 & 8 & 6.4 & \\
\hline $1: 10$ & 160 & 12 & 5 \\
\hline
\end{tabular}

It is clear that the nitrogen content at the graphene surface within our samples is close to that reported by other groups (Table 6) or even better taking into account that the GO: urea ratio was significantly lower.

\subsection{Electrochemical Studies}

Electrochemical studies regarding the reversibility of the redox process, the charge-transfer resistance and the apparent heterogeneous electron transfer rate constant of bare and graphene-modified electrodes are next presented and discussed. The first experiments were devoted to the calculation of the active area of each electrode. In order to achieve that, $\mathrm{CVs}$ were recorded with different scanning rates (from 2 to $50 \mathrm{mV} / \mathrm{s}$ ) in the presence of a redox indicator, $\mathrm{K}_{4}\left[\mathrm{Fe}(\mathrm{CN})_{6}\right]\left(10^{-3} \mathrm{M}\right.$ in $0.2 \mathrm{M} \mathrm{KCl}$ 
supporting electrolyte; Figure 7a-c). In the case of all NGr-modified electrodes (see for example GC/NGr-1 in Figure 7a and Table 7) well-defined anodic and cathodic peaks were obtained with a small peak potential separation $\left(\Delta \mathrm{E}_{\mathrm{p}}=76 \mathrm{mV}\right)$. In contrast, for the bare $\mathrm{GC}$ electrode the two waves were very broad and the peak potential separation large $(400 \mathrm{mV})$ (Figure $7 \mathrm{~b})$. GO modified electrode was a special case with a poorly defined electrochemical signal, confirming the GO insulating properties (Figure 7c).

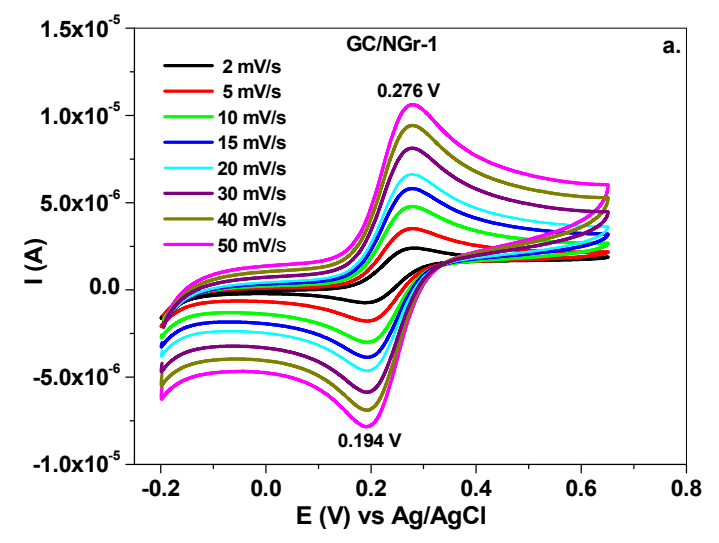

(a)

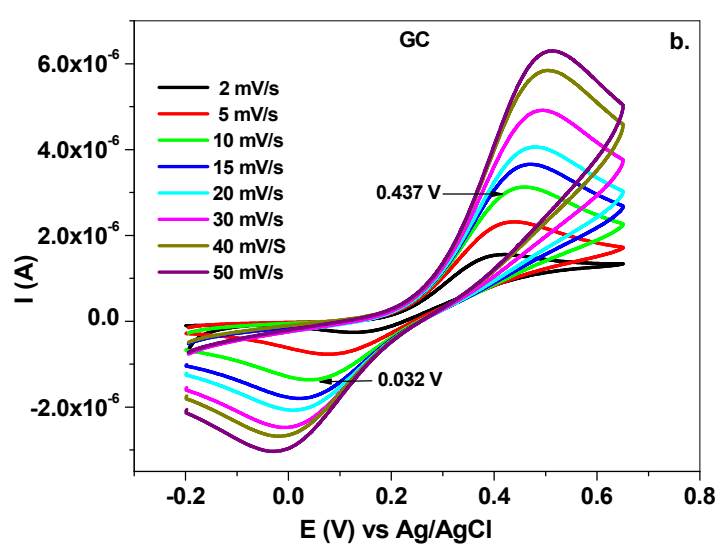

(b)

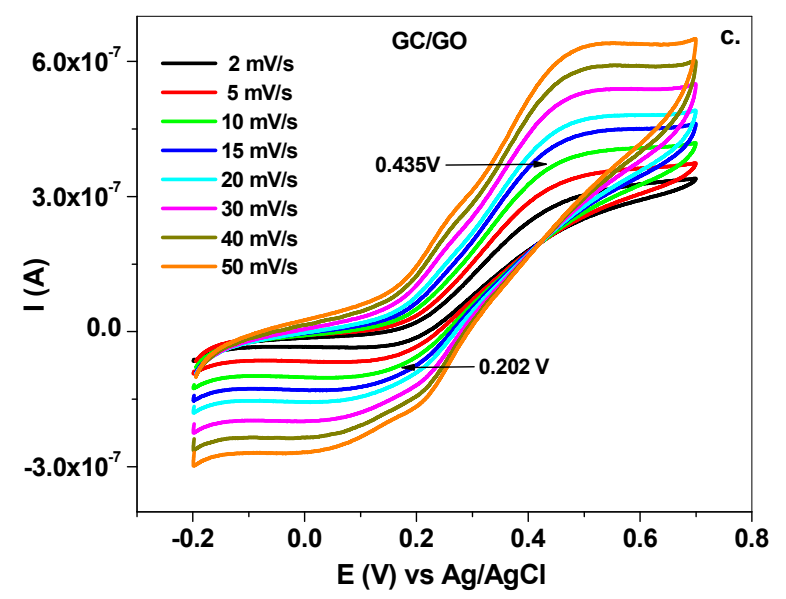

(c)

Figure 7. Cyclic voltammograms recorded with different electrodes: GC/NGr-1 (a), GC (b) and GC/GO (c) in $10^{-3} \mathrm{M} \mathrm{K}_{4}\left[\mathrm{Fe}(\mathrm{CN})_{6}\right](0.2 \mathrm{M} \mathrm{KCl}$ supporting electrolyte); scanning rate from 2 to $50 \mathrm{mV} / \mathrm{s}$.

Table 7. The electrochemical parameters of bare, GO- and NGr-modified electrodes.

\begin{tabular}{cccccccccc}
\hline Electrode & $\begin{array}{c}\mathbf{E}^{\mathbf{0}^{\prime}} \\
\mathbf{V}\end{array}$ & $\begin{array}{c}\Delta \mathbf{E}_{\mathbf{p}} \\
\mathbf{V}\end{array}$ & $\begin{array}{c}\mathbf{I}_{\mathbf{p a}} \\
\boldsymbol{\mu A}\end{array}$ & $\begin{array}{c}\mathbf{I}_{\mathbf{p c}} \\
\boldsymbol{\mu A}\end{array}$ & $\mathbf{I}_{\mathbf{p a}} / \mathbf{I}_{\mathbf{p c}}$ & $\begin{array}{c}\mathbf{Q}_{\mathbf{a}} \\
\boldsymbol{\mu C}\end{array}$ & $\begin{array}{c}\mathbf{Q}_{\mathbf{c}} \\
\boldsymbol{\mu C}\end{array}$ & $\begin{array}{c}\mathbf{A} \\
\mathbf{c m}^{2}\end{array}$ & $\begin{array}{c}\Gamma_{\mathbf{a}} \\
\mathbf{p m o l} / \mathbf{c m}^{2}\end{array}$ \\
\hline GC/NGr-1 & 0.238 & 0.076 & 3.711 & -3.554 & 1.04 & 0.755 & 0.648 & 0.05 & 156 \\
\hline GC/NGr-2 & 0.236 & 0.079 & 3.073 & -3.090 & 0.99 & 0.656 & 0.613 & 0.043 & 157 \\
\hline GC/NGr-3 & 0.235 & 0.081 & 2.698 & -2.714 & 0.99 & 0.609 & 0.562 & 0.036 & 175 \\
\hline GC & 0.254 & 0.366 & 1.789 & -1.493 & 1.19 & 0.394 & 0.536 & 0.02 & 204 \\
\hline GC/GO & 0.318 & 0.232 & 0.131 & -0.08 & 1.54 & 0.034 & 0.02 & 0.008 & 44 \\
\hline
\end{tabular}

$\mathrm{Q}_{\mathrm{a}}=$ Anodic Peak area; $\mathrm{Q}_{\mathrm{c}}=$ Cathodic Peak area; $\mathrm{A}=$ active area; $\mathrm{E}^{\mathrm{O}}$ - formal potential; $\Gamma_{\mathrm{a}}-$ surface coverage $\left(\mathrm{pmol} / \mathrm{cm}^{2}\right)$. 
The active area of the bare and NGr-modified electrodes was calculated using the slope of the corresponding $\left(\mathrm{I}_{\text {peak }}\right.$ ) vs. $\mathrm{v}^{1 / 2}$ plot [58], and the values can be found in Table 7 , along with other parameters derived from cyclic voltammetry (at a scan rate of $10 \mathrm{mV} / \mathrm{s}$ ). The smallest area was that corresponding to the GC/GO electrode $\left(0.008 \mathrm{~cm}^{2}\right)$, followed by bare GC $\left(0.02 \mathrm{~cm}^{2}\right)$. All NGr-modified electrodes had larger surface areas, varying from 0.036 to $0.05 \mathrm{~cm}^{2}$. The best characteristics were those of the GC/NGr-1 electrode ( $\mathrm{A}=0.05 \mathrm{~cm}^{2} ; \mathrm{I}_{\mathrm{pa}} / \mathrm{I}_{\mathrm{pc}} \sim 1$ and $\left.\Delta \mathrm{E}_{\mathrm{p}} \sim 76 \mathrm{mV} / \mathrm{n}\right)$, probably due to the highest concentration of pyrrolic-N among all N-doped graphene. On the other hand, for GC and GC/GO electrodes, the redox process can be considered as quasi-reversible $\left(\mathrm{I}_{\mathrm{pa}} / \mathrm{I}_{\mathrm{pc}}>1\right.$ and $\left.\Delta \mathrm{E}_{\mathrm{p}}>200 \mathrm{mV} / \mathrm{n}\right)$.

Another important parameter calculated from the recorded CVs was the surface coverage with the redox species during the anodic oxidation $\left(\Gamma_{a}\right)[59]$ :

$$
\Gamma_{a}=Q_{a} / n F A
$$

where $Q_{a}$ is the charge under the anodic peak (Coulomb), $n$ is number of transferred electrons $(\mathrm{n}=1)$, $F$ is the Faraday number $(96485 \mathrm{C} / \mathrm{mol})$ and $A$ is the active area $\left(\mathrm{cm}^{2}\right)$.

One can see that the largest surface coverage was obtained for bare GC electrode, followed by $\mathrm{N}$-doped graphene modified electrodes. This is an interesting result which may be explained by the well-known hydrophobicity of nitrogen-doped graphene. In fact, for GC/NGr-1 and GC/NGr-2 electrodes the $\Gamma_{a}$ values were similar and slightly lower than that corresponding to GC/NGr-3 (NGr-3 sample had the highest doping level, of $6.85 \mathrm{wt} \%$ ).

As expected, GC/GO had the lowest surface coverage of $44 \times 10^{-12} \mathrm{~mol} / \mathrm{cm}^{2}$. One of the reasons may be due to various oxygen-containing groups attached to the surface which hinder both the adsorption of redox species and the transfer of electrons. The surface coverage is well correlated with the current density $\left(\mathrm{A} / \mathrm{cm}^{2}\right)$ recorded with each electrode (Figure 8$)$. The largest current density was obtained with the bare GC electrode, followed by the NGr-modified electrodes and GC/GO electrode.

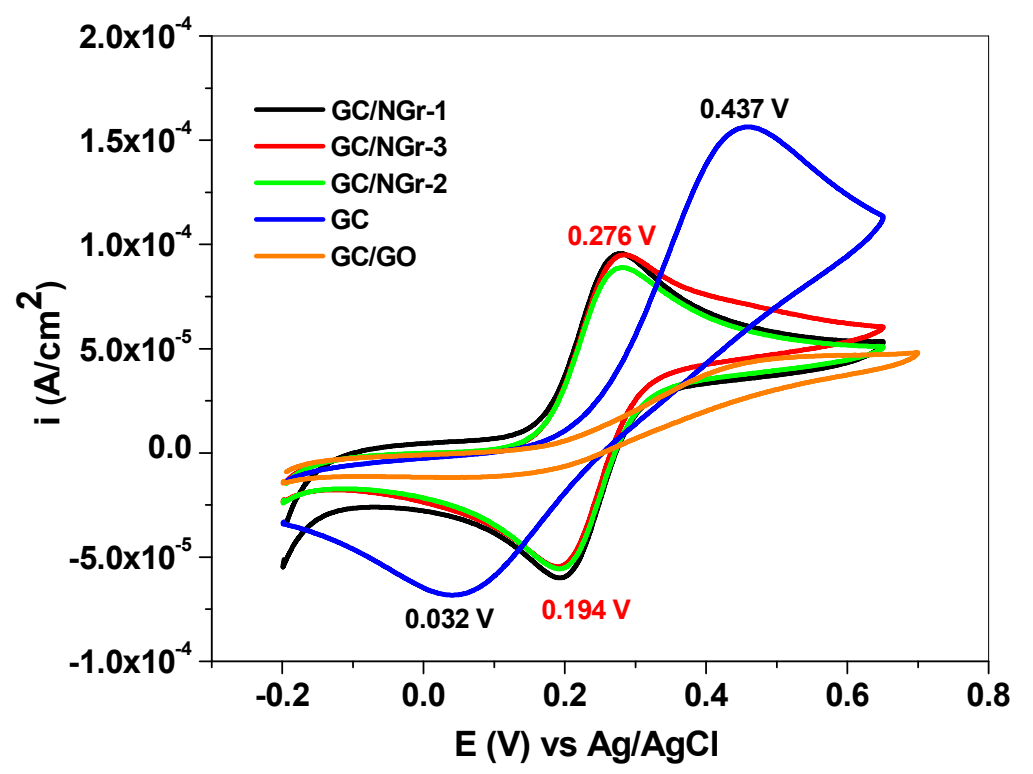

Figure 8. Comparison between the current densities of GC, GC/NGr and GC/GO electrodes in solution containing $10^{-3} \mathrm{M} \mathrm{K}_{4}\left[\mathrm{Fe}(\mathrm{CN})_{6}\right] ; 0.2 \mathrm{M} \mathrm{KCl}$ supporting electrolyte; $10 \mathrm{mV} / \mathrm{s}$ scan rate.

Next, the interfacial properties of bare and $\mathrm{N}$-doped graphene modified electrodes were evaluated using electrochemical impedance spectroscopy. The spectra were recorded in $10^{-3} \mathrm{M} \mathrm{K}_{4}\left[\mathrm{Fe}(\mathrm{CN})_{6}\right]$ $(0.2 \mathrm{M} \mathrm{KCl}$ supporting electrolyte) at a bias corresponding to the peak potential of each electrode $(+0.437$ $\mathrm{V}$ for GC and GC/GO; $+0.276 \mathrm{~V}$ for all NGr-modified electrodes) within $0.1-10^{6} \mathrm{~Hz}$ frequency range.

In Figure 9 are presented the Nyquist plots obtained with GC, GC/NGr and GC/GO electrodes. The bare GC electrode exhibits a semicircle in the high-medium frequencies, characteristic to the 
charge-transfer resistance $\left(\mathrm{R}_{\mathrm{ct}}\right)$, and a straight line at low frequencies, characteristic to the diffusion of the electro-active species towards the electrode/solution interface (Warburg impedance). In the case of the GC/GO electrode, the semicircle is highly extended due to the insulating properties of graphene oxide. In contrast, for the electrodes modified with nitrogen-doped graphene the impedance values decreased by one order of magnitude, both the semicircle and the diffusive line (see the inset in Figure 9). The experimental EIS data were fitted with modified Randles electrical equivalent circuits, presented in Figure 10.

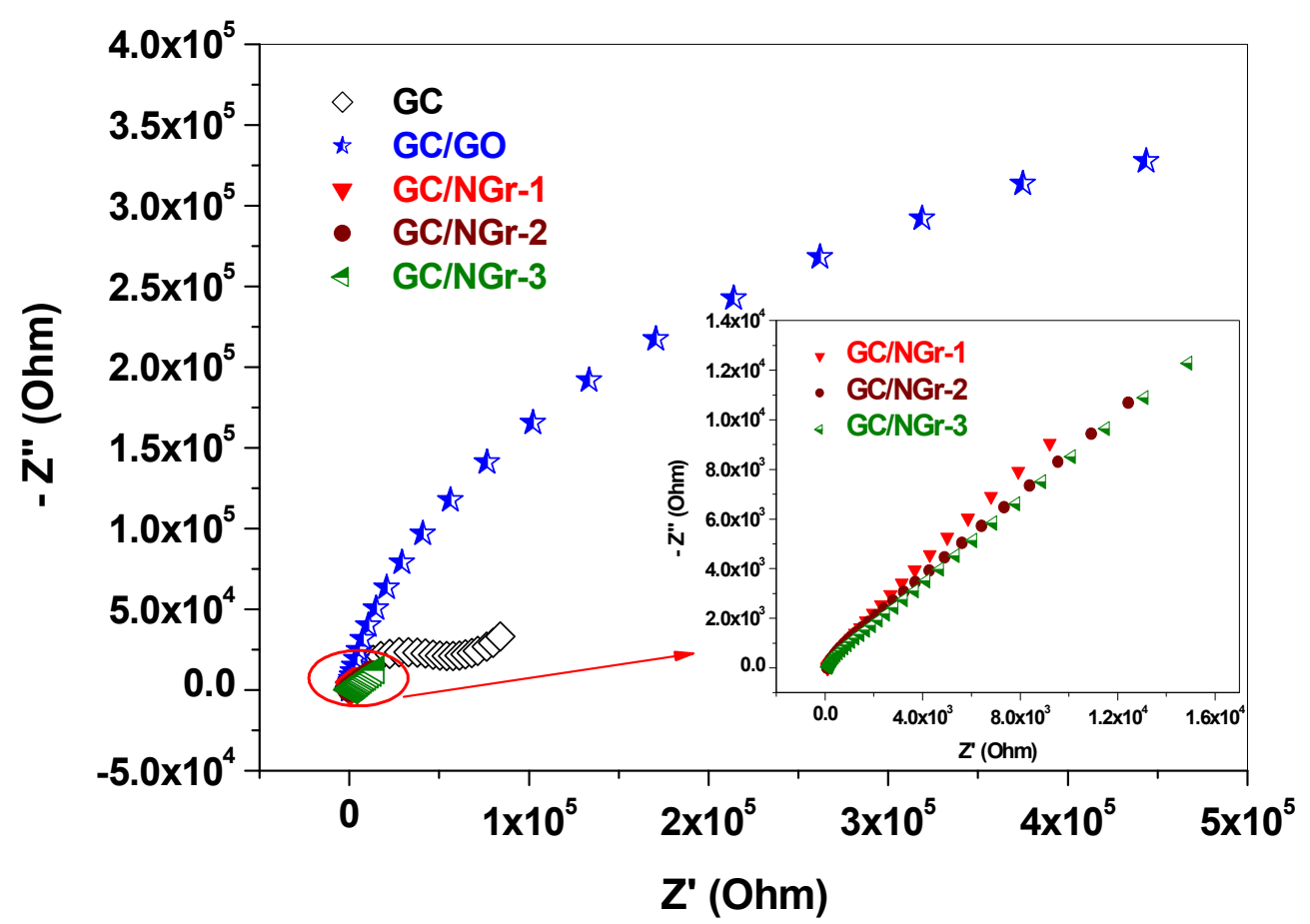

Figure 9. Nyquist plots obtained for GC, GC/GO and NGr-modified electrodes in $10^{-3} \mathrm{M} \mathrm{K}_{4}\left[\mathrm{Fe}(\mathrm{CN})_{6}\right]$ (0.2 M KCl supporting electrolyte); applied potential: $+0.437 \mathrm{~V}$ for GC and GC/GO; $+0.276 \mathrm{~V}$ for GC/NGr; $0.1-10^{6} \mathrm{~Hz}$ frequency range.

For the bare GC electrode, the best fit was obtained with a circuit containing the solution resistance $\left(R_{s}\right)$, the charge-transfer resistance at the electrode/solution interface $\left(R_{c t}\right)$, the Warburg impedance due to the diffusion of ions in solution $\left(\mathrm{Z}_{\mathrm{W}}\right)$ and a constant phase element (CPE) that models a non-ideal capacitor.

The CPE is expressed by:

$$
C P E=\frac{1}{A(\mathrm{j} \omega)^{\mathrm{n}}}
$$

where $\omega$ is the frequency, $\mathrm{j}=\sqrt{ }-1$, while $n$ and $A$ are constant parameters that result after fitting the experimental data with the proposed circuit. For $n=0, C P E$ behaves as a resistor, and for $n=1, C P E$ behaves as a capacitor.

The Warburg impedance appears in the Nyquist plot as a $45^{\circ}$ straight line and is expressed by:

$$
Z w=\frac{\sigma}{\sqrt{ } \omega}-\frac{j \sigma}{\sqrt{ } \omega}
$$

where $\sigma$ depends on the concentrations of the ionic species, the electrode area and the reaction kinetics. 

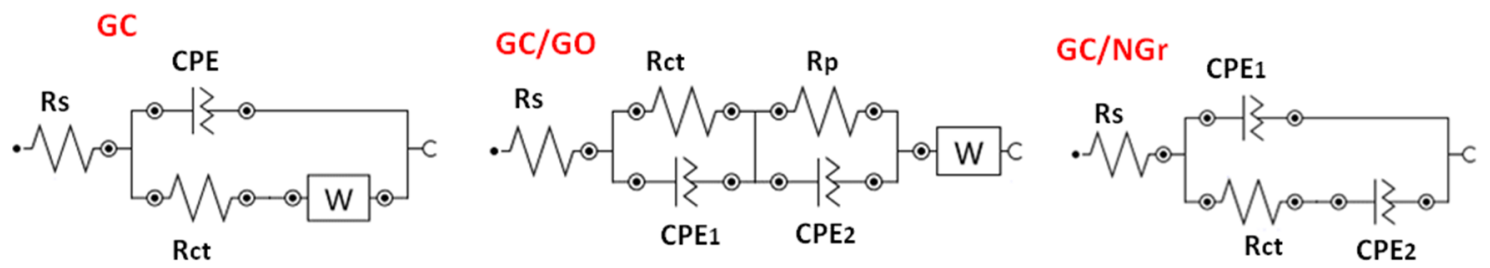

Figure 10. Modified Randles electrical equivalent circuits employed for fitting the experimental EIS data for GC, GC/GO and GC/NGr electrodes.

For the electrode modified with graphene oxide (GC/GO), the surface is significantly different from that of bare GC. The successive GO layers deposited on top of the substrate were forming a porous structure where the insertion of ions from solution was hindered by the surface charges. Therefore, the equivalent circuit was a more complex one and contained the solution resistance, two RC parallel circuits (where the capacitances were replaced by CPEs) and the Warburg impedance (Figure 10). One of the resistances was attributed to $R_{c t}$, while the other resistance, $R_{p}$, was attributed to the resistance of the porous structure to ions insertion.

In the case of electrodes modified with nitrogen-doped graphene, the surface is less hydrophilic but still has increased roughness compared with bare GC, and therefore, the best fit was obtained when the Warburg impedance was replaced with CPE, while the other circuit elements were preserved $\left(\mathrm{R}_{\mathrm{S}}, \mathrm{R}_{\mathrm{ct}}\right.$ and $\mathrm{CPE}_{1}$; Figure 10$)$.

The differences between the three electrical equivalent circuits may be attributed to the characteristic of each electrode/solution interface. Hence, graphene oxide has not only insulating properties but also oxygen-containing groups that repel the negatively charged redox species $\left.\left[\mathrm{Fe}(\mathrm{CN})_{6}\right]^{3-/ 4-}\right]$ and hinder the transfer of electrons. Consequently, the GC/GO electrode had the largest $R_{c t}$ value of all electrodes $\left(145 \times 10^{3}\right.$ Ohm, see Table 8$)$.

Table 8. The values of $\mathrm{R}_{\mathrm{ct}}$ and $\mathrm{K}_{\mathrm{app}}$ for bare and GC modified electrodes.

\begin{tabular}{cccccc}
\hline Electrode & GC/NGr-1 & GC/NGr-2 & GC/NGr-3 & GC & GC/GO \\
\hline $\mathbf{R}_{\text {ct }}(\mathbf{O h m})$ & 38.3 & 257 & 112 & $50.9 \times 10^{3}$ & $145 \times 10^{3}$ \\
\hline $\mathbf{K}_{\text {app }}(\mathbf{c m} / \mathbf{s})$ & $13.9 \times 10^{-2}$ & $2.39 \times 10^{-2}$ & $6.55 \times 10^{-2}$ & $2.6 \times 10^{-4}$ & $2.1 \times 10^{-4}$ \\
\hline
\end{tabular}

A different situation can be found in the case of electrodes modified with nitrogen-doped graphene. The chemical synthesis led to the formation of few-layer graphene containing $6.36-6.85 \mathrm{wt} \%$ of nitrogen, with a different proportion of pyrrolic-N,pyridinic-N and graphitic-N (see the XPS results). According to the literature $[40,60]$, the incorporated nitrogen atoms induced changes at the Fermi level by opening the band gap of graphene and enhancing the charge transfer. Moreover, the carbon atoms which are in close vicinity to the heteroatom may be positively charged due to the higher electronic affinity of nitrogen. As a consequence, the negatively charged species from the solution, $\left[\mathrm{Fe}(\mathrm{CN})_{6}\right]^{3-}$, may easily transfer the electrons. The determined $R_{\mathrm{ct}}$ values are indeed significantly lower for all GC/NGr electrodes, in comparison with the bare GC or GC/GO electrode. This is also in excellent agreement with the previous electrochemical measurements, where the CVs recorded with the GC/NGr electrodes exhibits the characteristics of a reversible redox process (see Figure 8).

The value of apparent heterogeneous electron transfer rate constant $\left(K_{a p p}\right)$ calculated for each electrode (Equation (6)) [61] gives also valuable information about the charge-transfer at electrode/solution interface (see Table 8).

$$
\mathrm{K}_{\mathrm{app}}=\frac{\mathrm{RT}}{\mathrm{n}^{2} \mathrm{~F}^{2} \mathrm{AR} \mathrm{R}_{\mathrm{ct}} \mathrm{C}}
$$

where $\mathrm{R}$ is the ideal gas constant $(8.314 \mathrm{Joule} /(\mathrm{mol} \cdot \mathrm{K}))$; $\mathrm{T}$ is the temperature $(298 \mathrm{~K}) ; \mathrm{F}$ is the Faraday constant $(96485 \mathrm{C} / \mathrm{mol}) ; n$ is the number of electrons transferred during the redox reaction $(n=1)$; $\mathrm{A}$ 
is the active area of the electrode $\left(\mathrm{cm}^{2}\right) ; \mathrm{R}_{\mathrm{ct}}$ is the charge-transfer resistance obtained from the fitted Nyquist plots $(\Omega)$; C is the concentration of the redox species $\left(\mathrm{mol} / \mathrm{cm}^{3}\right)$.

Its value has the same order of magnitude for GC/GO and bare GC $\left(2.1-2.6 \times 10^{-4} \mathrm{~cm} / \mathrm{s}\right)$ but is considerably higher for all NGr-modified electrodes $\left(6.55-13.9 \times 10^{-2} \mathrm{~cm} / \mathrm{s}\right)$. The largest value was that corresponding to NGr-1 material, which had the lowest doping level and the highest concentration of pyrrolic-N, among all nitrogen-doped graphene.

\subsection{Electrochemical Detection of 8-OHdG with Bare and Graphene-Modified Electrodes}

In order to further investigate the electrocatalytic properties of nitrogen-doped graphene and graphene oxide samples, the modified electrodes were tested towards the detection of a cancer biomarker, 8-OHdG. For the beginning, cyclic voltammograms were recorded with each electrode in pH6 PBS solution (scan rate $10 \mathrm{mV} / \mathrm{s}$ ) and the results are shown in Figure S1 (Supplementary Material). Important information can be obtained from these $C V$ s related to the capacitive current $\left(I_{c}\right)$, which reflect the charge-storage capability of the synthesized materials. Hence, the graphene samples with the lowest doping level (GC/NGr-1 and GC/NGr-2) have the largest capacitive current, of $1.15 \times 10^{-7} \mathrm{~A}$ and $1.01 \times 10^{-7} \mathrm{~A}$, respectively. In comparison, all the other samples have lower values, such as $5.58 \times$ $10^{-8} \mathrm{~A}(\mathrm{GC} / \mathrm{NGr}-3), 1.48 \times 10^{-8} \mathrm{~A}(\mathrm{GC} / \mathrm{GO})$ and $2.39 \times 10^{-8} \mathrm{~A}$ (GC; see also Table S1). The rest potential (or open-circuit potential) of each electrode was also determined before recording the corresponding $\mathrm{CV}$, and the values are listed in Table S1. The GC/NGr-1 and GC/NGr-2 electrodes have identical rest potential $(0.36 \mathrm{~V})$ in good agreement with the doping level. A slightly higher value was obtained for the GC/NGr-3 electrode $(0.38 \mathrm{~V})$, while for GC/GO and bare GC the values were lower $(0.33$ and $0.27 \mathrm{~V}$, respectively).

Next, linear sweep voltammograms were recorded with each electrode in solutions containing various concentrations of $8-\mathrm{OHdG}\left(10^{-7}-10^{-3} \mathrm{M}\right)$ in $\mathrm{pH} 6$ PBS supporting electrolyte (scan rate 10 $\mathrm{mV} / \mathrm{s}$; see Figure S2a for electrode GC/NGr-1). The corresponding calibration plots are represented in Figure S2b and c. One can observe that there is excellent agreement between the peak current of each electrode and the corresponding $\mathrm{R}_{\mathrm{ct}}$ and $\mathrm{K}_{\mathrm{app}}$ values. Hence, among all nitrogen-doped materials, the sample with the lowest $R_{\mathrm{ct}}$ and highest $K_{\text {app }}$ has the best electrochemical response (GC/NGr-1). It is followed by GC/NGr-3, GC/NGr-2 and bare GC. The poorest electrochemical signal was obtained with the GC/GO electrode, due to the insulating properties of graphene oxide. The electrochemical parameters obtained from the calibration plots (limit of detection, sensitivity and linear range) for bare and graphene-modified electrodes are listed in Table S1, further indicating that the doping level may critically influence the performances of the nitrogen-doped graphene.

\section{Conclusions}

Nitrogen-doped graphenes with various concentrations of heteroatom (6.36, 6.37 and $6.85 \mathrm{wt} . \%)$ were prepared using the hydrothermal method with urea as reducing/doping source for graphene oxide. The structural characterization of the synthesized materials revealed that after doping, significant changes occurred in the XRD, Raman and XPS spectra, confirming the presence of heteroatom. For exemplification, the largest value for the in-plane crystallite size $\left(L_{a}\right)$ was obtained for GO $(17.11 \mathrm{~nm})$, followed by the NGr-1 $(16.24 \mathrm{~nm})$ and NGr-2 $(16.16 \mathrm{~nm})$ samples, which according to elemental analysis had similar amounts of nitrogen (6.36 wt\%). For NGr-3 sample, the $\mathrm{L}_{\mathrm{a}}$ value is slightly lower $(16.12 \mathrm{~nm})$, being in good agreement with the higher doping level (6.85 wt\%). In addition, the EIS studies conducted with NGr-modified electrodes indicated that the sample with the lowest doping level and the highest concentration of pyrrolic-N among all nitrogen-doped graphene (NGr-1) exhibits the best electrochemical parameters: a very small $R_{\mathrm{ct}}(38.3 \Omega)$, a large $K_{\mathrm{app}}\left(13.9 \times 10^{-2} \mathrm{~cm} / \mathrm{s}\right)$ and a low detection limit $\left(9 \times 10^{-8} \mathrm{M}\right)$ for 8-OHdG.

Supplementary Materials: The following are available online at http://www.mdpi.com/1424-8220/20/7/1815/s1, Figure S1: Cyclic voltammograms recorded with bare and graphene-modified electrodes in pH 6 PBS solution; scan rate $10 \mathrm{mV} / \mathrm{s}$, Figure S2: Linear sweep voltammograms recorded with GC/NGr-1 electrode in solutions 
containing various concentrations of $8-\mathrm{OHdG}, 10^{-7}-10^{-3} \mathrm{M}$; pH6 PBS supporting electrolyte; scan rate $10 \mathrm{mV} / \mathrm{s}$ (a); the corresponding calibration plots for $8-\mathrm{OHdG}$ obtained with bare GC and nitrogen-doped graphene modified electrodes (b); the calibration plot for 8-OHdG obtained with GC/GO electrode (c). Table S1: Electrochemical parameters obtained from CVs (Figure S1) and calibration plots (Figure S2) for bare and graphene-modified electrodes.

Author Contributions: M.C. synthesized the nitrogen-doped graphene samples and wrote the corresponding paragraph, C.V. and F.P. performed the electrochemical measurements, E.G. carried out the elemental analysis and S.M.P. wrote and edited the final manuscript. All authors have read and agreed to the published version of the manuscript.

Funding: This work was supported by a grant from the Romanian Ministry of Research and Innovation, CNCS-UEFISCDI, project number PN-III-P4-ID-PCCF-2016-0006, within PNCDI III. SEM measurements were partially supported through the infrastructure obtained in a project at the Research Center and Advanced Technologies for Alternative Energies-CETATEA-623/11.03.2014.

Acknowledgments: The authors are grateful to Cristian Leostean for recording the XPS measurements and to Teodora Radu for useful discussions regarding the XPS results, to PhD student Alexandru Turza for recording the XRD spectra, to Camelia Grosan for recording the Raman spectra and to Maria Suciu for SEM analysis.

Conflicts of Interest: The authors declare no conflict of interest.

\section{References}

1. Shams, S.S.; Zhang, R.; Zhu, J. Graphene synthesis: A Review. Mater. Sci. Pol. 2015, 33, 566-578. [CrossRef]

2. Cen, C.; Zhang, Y.; Chen, X.; Yang, H.; Yi, Z.; Yao, W.; Tang, Y.; Yi, Y.; Wang, J.; Wu, P. A dual-band metamaterial absorber for graphene surface plasmon resonance at terahertz frequency. Phys. E Low-Dimens. Syst. Nanostruct. 2020, 117, 113840. [CrossRef]

3. Cen, C.; Chen, Z.; Xu, D.; Jiang, L.; Chen, X.; Yi, Z.; Wu, P.; Li, G.; Yi, Y. High quality factor, high sensitivity metamaterial graphene-Perfect absorber based on critical coupling theory and impedance matching. Nanomaterials 2020, 10, 95. [CrossRef]

4. Kaur, M.; Kaur, M.; Sharma, V.K. Nitrogen-doped graphene and graphene quantum dots: A review onsynthesis and applications in energy, sensors and environment. Adv. Colloid Interface Sci. 2018, 259, 44-64. [CrossRef]

5. Damodar, D.; Kumar, S.K.; Martha, S.K.; Deshpande, A.S. Nitrogen-doped graphene-like carbon nanosheets from commercial glue: Morphology, phase evolution and Li-ion battery performance. Dalt. Trans. 2018, 47, 12218-12227. [CrossRef]

6. Agnoli, S.; Favaro, M. Doping graphene with boron: A review of synthesis methods, physicochemical characterization, and emerging applications. J. Mater. Chem. A 2016, 4, 5002-5025. [CrossRef]

7. Thaweesak, S.; Wang, S.; Lyu, M.; Xiao, M.; Peerakiatkhajohn, P.; Wang, L. Boron-doped graphitic carbon nitride nanosheets for enhanced visible light photocatalytic water splitting. Dalt. Trans. 2017, 46, 10714-10720. [CrossRef] [PubMed]

8. Kiciński, W.; Szala, M.; Bystrzejewski, M. Sulfur-doped porous carbons: Synthesis and applications. Carbon 2014, 68, 1-32. [CrossRef]

9. Chen, L.; Cui, X.; Wang, Y.; Wang, M.; Qiu, R.; Shu, Z.; Zhang, L.; Hua, Z.; Cui, F.; Wei, C.; et al. One-step synthesis of sulfur doped graphene foam for oxygen reduction reactions. Dalt. Trans. 2014, 43, 3420-3423. [CrossRef]

10. Kakaei, K.; Balavandi, A. Synthesis of halogen-doped reduced graphene oxide nanosheets as highly efficient metal-free electrocatalyst for oxygen reduction reaction. J. Colloid Interface Sci. 2016, 463, 46-54. [CrossRef] [PubMed]

11. Ren, Z.; Hu, D.; Zhang, X.; Liu, D.; Wang, C. Hierarchical porous hollow FeFe $(\mathrm{CN})_{6}$ nanospheres wrapped with I-doped graphene as anode materials for lithium-ion batteries. Dalt. Trans. 2019, 48, 4058-4066. [CrossRef] [PubMed]

12. Lu, Z.J.; Bao, S.J.; Gou, Y.T.; Cai, C.J.; Ji, C.C.; Xu, M.W.; Song, J.; Wang, R. Nitrogen-doped reduced-graphene oxide as an efficient metal-free electrocatalyst for oxygen reduction in fuel cells. RSC Adv. 2013, 3, 3990-3995. [CrossRef]

13. Xiong, D.; Li, X.; Bai, Z.; Shan, H.; Fan, L.; Wu, C.; Li, D.; Lu, S. Superior cathode performance of nitrogen-doped graphene frameworks for lithium ion batteries. ACS Appl. Mater. Interfaces 2017, 9, 10643-10651. [CrossRef] [PubMed] 
14. Elessawy, N.A.; El Nady, J.; Wazeer, W.; Kashyout, A.B. Development of high-performance supercapacitor based on a novel controllable green synthesis for 3D nitrogen doped graphene. Sci. Rep. 2019, 9, 1129. [CrossRef]

15. Li, X.; Zhao, Q.; Feng, X.; Pan, L.; Wu, Z.; Wu, X.; Ma, T.; Liu, J.; Pan, Y.; Song, Y.; et al. Pyridinic nitrogen-doped graphene nanoshells boost the catalytic efficiency of palladium nanoparticles for the $\mathrm{N}$-allylation reaction. ChemSusChem 2019, 12, 858-865. [CrossRef]

16. Oh, T.; Ryu, S.; Oh, H.; Kim, J. $\mathrm{MnCo}_{2} \mathrm{O}_{4}$ nanoparticles supported on nitrogen and sulfur co-doped mesoporous carbon spheres as efficient electrocatalysts for oxygen catalytic reactions. Dalt. Trans. 2019, 48, 945-953. [CrossRef]

17. Sheng, Z.H.; Shao, L.; Chen, J.J.; Bao, W.J.; Wang, F.B.; Xia, X.H. Catalyst-free synthesis of nitrogen-doped graphene via thermal annealing graphite oxide with melamine and its excellent electrocatalysis. ACS Nano 2011, 5, 4350-4358. [CrossRef]

18. Wakeland, S.; Martinez, R.; Grey, J.K.; Luhrs, C.C. Production of graphene from graphite oxide using urea as expansion-reduction agent. Carbon 2010, 48, 3463-3470. [CrossRef]

19. Wang, L.; Sofer, Z.; Luxa, J.; Pumera, M. Nitrogen doped graphene: Influence of precursors and conditions of the synthesis. J. Mater. Chem. C 2014, 2, 2887-2893. [CrossRef]

20. Deng, D.; Pan, X.; Yu, L.; Cui, Y.; Jiang, Y.; Qi, J.; Li, W.X.; Fu, Q.; Ma, X.; Xue, Q.; et al. Toward N-doped graphene via solvothermal synthesis. Chem. Mater. 2011, 23, 1188-1193. [CrossRef]

21. Shazali, S.S.; MohdZubir, M.N.; Rozali, S.; Zabri, M.Z.; Sabri, M.F.M.; Amiri, A. Facile hydrothermal method for synthesizing nitrogen-doped graphene nanoplatelets using aqueous ammonia: Dispersion, stability in solvents and thermophysical performances. Mater. Res. Express 2018, 5, 035042. [CrossRef]

22. Magerusan, L.; Socaci, C.; Pogacean, F.; Rosu, M.C.; Biris, A.R.; Coros, M.; Turza, A.; Floare-Avram, V.; Katona, G.; Pruneanu, S. Enhancement of peroxidase-like activity of N-doped graphene assembled with iron-tetrapyridylporphyrin. RSC Adv. 2016, 6, 79497-79506. [CrossRef]

23. Yanilmaz, A.; Tomak, A.; Akbali, B.; Bacaksiz, C.; Ozceri, E.; Ari, O.; Senger, R.T.; Selamet, Y.; Zareie, H.M. Nitrogen doping for facile and effective modification of graphene surfaces. RSC Adv. 2017, 7, 28383-28392. [CrossRef]

24. Bundaleska, N.; Henriques, J.; Abrashev, M.; Botelho do Rego, A.M.; Ferraria, A.M.; Almeida, A.; Dias, F.M.; Valcheva, E.; Arnaudov, B.; Upadhyay, K.K.; et al. Large-scale synthesis of free-standing N-doped graphene using microwave plasma. Sci. Rep. 2018, 8, 12595. [CrossRef]

25. Mao, Y.; Zhao, C.; Ge, S.; Luo, T.; Chen, J.; Liu, J.; Xi, F.; Liu, J. Gram-scale synthesis of nitrogen doped graphene quantum dots for sensitive detection of mercury ions and L-cysteine. RSC Adv. 2019, 9, 32977-32983. [CrossRef]

26. Xie, Z.; Zhu, J.; Bi, Y.; Ren, H.; Chen, X.; Yu, H. Nitrogen-doped porous graphene-based aerogels toward efficient heavy metal ion adsorption and supercapacitor applications. Phys. Status Solidi Rapid Res. Lett. 2020, 14, 1900534. [CrossRef]

27. Suhag, D.; Singh, A.; Chattopadhyay, S.; Chakrabarti, S.; Mukherjee, M. Hydrothermal synthesis of nitrogen doped graphene nanosheets from carbon nanosheets with enhanced electrocatalytic properties. RSC Adv. 2015, 5, 39705-39713. [CrossRef]

28. Ren, H.; Shi, X.; Zhu, J.; Zhang, Y.; Bi, Y.; Zhang, L. Facile synthesis of N-doped graphene aerogel and its application for organic solvent adsorption. J. Mater. Sci. 2016, 51, 6419-6427. [CrossRef]

29. Long, D.; Li, W.; Ling, L.; Miyawaki, J.; Mochida, I.; Yoon, S.H. Preparation of nitrogen-doped graphene sheets by a combined chemical and hydrothermal reduction of graphene oxide. Langmuir 2010, 26, 16096-16102. [CrossRef]

30. Zhang, H.; Kuila, T.; Kim, N.H.; Yu, D.S.; Lee, J.H. Simultaneous reduction, exfoliation, and nitrogen doping of graphene oxide via a hydrothermal reaction for energy storage electrode materials. Carbon 2014, 69, 66-78. [CrossRef]

31. Zhang, Y.; Wen, G.; Gao, P.; Bi, S.; Tang, X.; Wang, D. High-performance supercapacitor of macroscopic graphene hydrogels by partial reduction and nitrogen doping of graphene oxide. Electrochim. Acta 2016, 221, 167-176. [CrossRef]

32. Zhou, J.; Chen, Y.; Li, H.; Dugnani, R.; Du, Q.; UrRehman, H.; Kang, H.; Liu, H. Facile synthesis of three-dimensional lightweight nitrogen-doped graphene aerogel with excellent electromagnetic wave absorption properties. J. Mater. Sci. 2018, 53, 4067-4077. [CrossRef] 
33. ZangenehKamali, K.; Moradi Golsheikh, A. Green and facile approach to synthesis of well-dispersed nitrogen-doped graphene without using surfactant or stabilizer with potential application for oxygen reduction reaction. Colloids Surfaces A Physicochem. Eng. Asp. 2016, 509, 574-582. [CrossRef]

34. Wang, T.; Wang, L.; Wu, D.; Xia, W.; Zhao, H.; Jia, D. Hydrothermal synthesis of nitrogen-doped graphene hydrogels using amino acids with different acidities as doping agents. J. Mater. Chem. A 2014, 2, 8352-8361. [CrossRef]

35. Xing, Z.; Ju, Z.; Zhao, Y.; Wan, J.; Zhu, Y.; Qiang, Y.; Qian, Y. One-pot hydrothermal synthesis of Nitrogen-doped graphene as high-performance anode materials for lithium ion batteries. Sci. Rep. 2016, 6, 26146. [CrossRef]

36. Wang, H.; Maiyalagan, T.; Wang, X. Review on recent progress in nitrogen-doped graphene: Synthesis, characterization, and its potential applications. ACS Catal. 2012, 2, 781-794. [CrossRef]

37. Balandin, A.A.; Ghosh, S.; Bao, W.; Calizo, I.; Teweldebrhan, D.; Miao, F.; Lau, C.N. Superior thermal conductivity of single-layer graphene. Nano Lett. 2008, 8, 902-907. [CrossRef]

38. Zhang, Q.; Zhao, Q.; Fu, M.; Fan, X.; Lu, H.; Wang, H.; Zhang, Y.; Wang, H. Carbon quantum dots encapsulated in super small platinum nanocrystals core-shell architecture/nitrogen doped graphene hybrid nanocomposite for electrochemical biosensing of DNA damage biomarker-8-hydroxy-2'-deoxyguanosine. Anal. Chim. Acta 2019, 1047, 9-20. [CrossRef]

39. Tian, H.; Wang, L.; Sofer, Z.; Pumera, M.; Bonanni, A. Doped graphene for DNA analysis: The electrochemical signal is strongly influenced by the kind of dopant and the nucleobase structure. Sci. Rep. 2016, 6, 33046. [CrossRef]

40. Shao, Y.; Zhang, S.; Engelhard, M.H.; Li, G.; Shao, G.; Wang, Y.; Liu, J.; Aksay, I.A.; Lin, Y. Nitrogen-doped graphene and its electrochemical applications. J. Mater. Chem. 2010, 20, 7491-7496. [CrossRef]

41. Zhu, J.; Yang, X.; Fu, Z.; He, J.; Wang, C.; Wu, W.; Zhang, L. Three-dimensional macroassemblyof sandwich-like, hierarchical, porous carbon/graphene nanosheets towards ultralight, superhigh surface area, multifunctional aerogels. Chem. A Eur. J. 2016, 22, 2515-2524. [CrossRef] [PubMed]

42. Pogacean, F.; Socaci, C.; Pruneanu, S.; Biris, A.R.; Coros, M.; Magerusan, L.; Katona, G.; Turcu, R.; Borodi, G. Graphene based nanomaterials as chemical sensors for hydrogen peroxide-A comparison study of their intrinsic peroxidase catalytic behavior. Sens. Actuators B Chem. 2015, 213, 474-483. [CrossRef]

43. Magerusan, L.; Pogacean, F.; Socaci, C.; Coros, M.; Rosu, M.-C.; Pruneanu, S. Charge transfer-resistance in nitrogen-doped/undoped graphene: Its influence on the electro-catalytic reduction of $\mathrm{H}_{2} \mathrm{O}_{2}$. Electrochim. Acta 2016, 220, 664-671. [CrossRef]

44. Coroş, M.; Pogăcean, F.; Roşu, M.-C.; Socaci, C.; Borodi, G.; Mageruşan, L.; Biriş, A.R.; Pruneanu, S. Simple and cost-effective synthesis of graphene by electrochemical exfoliation of graphite rods. RSC Adv. 2016, 6, 2651-2661. [CrossRef]

45. Razeghi, M.; Pircheraghi, G. TPU/graphene nanocomposites: Effect of graphene functionality on the morphology of separated hard domains in thermoplastic polyurethane. Polymer 2018, 148, 169-180. [CrossRef]

46. Ferrari, A.C.; Basko, D.M. Raman spectroscopy as a versatile tool for studying the properties of graphene. Nat. Nanotechnol. 2013, 8, 235-246. [CrossRef]

47. Canado, L.G.; Takai, K.; Enoki, T.; Endo, M.; Kim, Y.A.; Mizusaki, H.; Jorio, A.; Coelho, L.N.; Magalhães-Paniago, R.; Pimenta, M.A. General equation for the determination of the crystallite size la of nanographite by Raman spectroscopy. Appl. Phys. Lett. 2006, 88, 163106. [CrossRef]

48. Xue, Y.; Liu, J.; Chen, H.; Wang, R.; Li, D.; Qu, J.; Dai, L. Nitrogen-doped graphene foams as metal-free counter electrodes in high-performance dye-sensitized solar cells. Angew. Chem. Int. Ed. 2012, 51, 12124-12127. [CrossRef]

49. Geng, D.; Yang, S.; Zhang, Y.; Yang, J.; Liu, J.; Li, R.; Sham, T.K.; Sun, X.; Ye, S.; Knights, S. Nitrogen doping effects on the structure of graphene. Appl. Surf. Sci. 2011, 257, 9193-9198. [CrossRef]

50. Shang, Y.; Xu, H.; Li, M.; Zhang, G. Preparation of N-doped graphene by hydrothermal method and interpretation of N-doped mechanism. Nano 2017, 12, 1750018. [CrossRef]

51. Agusu, L.; Ahmad, L.O.; Nurdin, M.; Mitsudo, S.; Kikuchi, H. Hydrothermal synthesis of reduced graphene oxide using urea as reduction agent: Excellent $\mathrm{X}$-band electromagnetic absorption properties. In Proceedings of the 5th International Conference on Advanced Materials Sciences and Technology (ICAMST 2017), Makassar, Indonesia, 19-20 September 2017; Volume 367. 
52. Zhang, Y.; Sun, Z.; Wang, H.; Wang, Y.; Liang, M.; Xue, S. Nitrogen-doped graphene as a cathode material for dye-sensitized solar cells: Effects of hydrothermal reaction and annealing on electrocatalytic performance. RSC Adv. 2015, 5, 10430-10439. [CrossRef]

53. Zeraatkar Moghaddam, A.; Ghiamati, E.; Pakar, R.; Sabouri, M.R.; Ganjali, M.R. A novel and an efficient 3-D high nitrogen doped graphene oxide adsorbent for the removal of congo red from aqueous solutions. Pollution 2019, 5, 501-514.

54. Tian, C.; Sun, L.; Wang, L.; Li, M.; Shi, K.; Xie, Y.; Fu, H.; Tan, T. Nitrogen-doped graphene with high nitrogen level via a one-step hydrothermal reaction of graphene oxide with urea for superior capacitive energy storage. RSC Adv. 2012, 2, 4498-4506.

55. Xu, X.; Zhou, Y.; Yuan, T.; Li, Y. Methanol electrocatalytic oxidation on Pt nanoparticles on nitrogen doped graphene prepared by the hydrothermal reaction of graphene oxide with urea. Electrochim. Acta 2013, 112, 587-595. [CrossRef]

56. Guo, H.L.; Su, P.; Kang, X.; Ning, S.K. Synthesis and characterization of nitrogen-doped graphene hydrogels by hydrothermal route with urea as reducing-doping agents. J. Mater. Chem. A 2013, 1, 2248-2255. [CrossRef]

57. Chen, X.L.; Wu, N.; Gou, G.Z.; Shi, L.; Pan, S.Q.; Liu, W. Large-scale growth of nitrogen-doped via solvothermal synthesis. Appl. Mech. Mater. 2014, 670-671, 323-326. [CrossRef]

58. Ferrari, A.G.M.; Foster, C.W.; Kelly, P.J.; Brownson, D.A.C.; Banks, C.E. Determination of the electrochemical area of screen-printed electrochemical sensing platforms. Biosensors 2018, 8, 53. [CrossRef]

59. Bard, A.J.; Faulkner, L.R. Electrochemical Methods: Fundamentals and Applications, 2nd ed.; John Wiley \& Sons, Inc.: Hoboken, NJ, USA, 2001.

60. Wang, Y.; Shao, Y.; Matson, D.W.; Li, J.; Lin, Y. Nitrogen-doped graphene and its biosensing. ACS Nano 2010, 4, 1790-1798. [CrossRef]

61. Nkosi, D.; Pillay, J.; Ozoemena, K.I.; Nouneh, K.; Oyama, M. Heterogeneous electron transfer kinetics and electrocatalytic behaviour of mixed self-assembled ferrocenes and SWCNT layers. Phys. Chem. Chem. Phys. 2010, 12, 604-613. [CrossRef]

(C) 2020 by the authors. Licensee MDPI, Basel, Switzerland. This article is an open access article distributed under the terms and conditions of the Creative Commons Attribution (CC BY) license (http://creativecommons.org/licenses/by/4.0/). 